\title{
Digital Transformation in Indian Insurance Industry - A Case Study
}

\author{
Jayameena Desikan ${ }^{1}$, \& A. Jayanthila Devi ${ }^{2}$ \\ ${ }^{1}$ Research Scholar, College of Computer Science and Information Science, \\ Srinivas University, Mangalore, India. \\ Orcid ID: 0000-0003-4592-2722; E-mail: meethu_8@yahoo.com \\ ${ }^{2}$ Professor, College of Computer Science \& Information Science, Srinivas University, \\ Mangalore, India. \\ Orcid ID: 0000-0002-6023-3899; E-mail: drjayanthila@gmail.com
}

Area of the Paper: Computer Science

Type of the Paper: Research Case Study

Type of Review: Peer Reviewed as per $|\mathrm{C}| \mathrm{O}|\mathrm{P}| \mathrm{E} \mid$ guidance.

Indexed In: OpenAIRE.

DOI: https://doi.org/10.5281/zenodo.5607469

Google Scholar Citation: IJCSBE

\section{How to Cite this Paper:}

Jayameena Desikan, \& Jayanthila Devi, A. (2021). Digital Transformation in Indian Insurance Industry - A Case Study. International Journal of Case Studies in Business, IT, and Education (IJCSBE), 5(2), 184-196. DOI: https://doi.org/10.5281/zenodo.5607469

International Journal of Case Studies in Business, IT and Education (IJCSBE)

A Refereed International Journal of Srinivas University, India.

Crossref DOI : https://doi.org/10.47992/IJCSBE.2581.6942.0128

(C) With Authors.

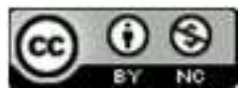

This work is licensed under a Creative Commons Attribution Non-Commercial 4.0 International License subject to proper citation to the publication source of the work.

Disclaimer: The scholarly papers as reviewed and published by the Srinivas Publications (S.P.), India are the views and opinions of their respective authors and are not the views or opinions of the S.P. The S.P. disclaims of any harm or loss caused due to the published content to any party. 


\title{
Digital Transformation in Indian Insurance Industry - A Case Study
}

\author{
Jayameena Desikan ${ }^{1}, \&$ A. Jayanthila Devi ${ }^{2}$ \\ ${ }^{1}$ Research Scholar, College of Computer Science and Information Science, \\ Srinivas University, Mangalore, India. \\ Orcid ID: 0000-0003-4592-2722; E-mail: meethu_8@yahoo.com \\ ${ }^{2}$ Professor, College of Computer Science \& Information Science, Srinivas University, \\ Mangalore, India. \\ Orcid ID: 0000-0002-6023-3899; E-mail: drjayanthila@ gmail.com
}

\begin{abstract}
Purpose: In India, the insurance industry has grown rapidly in the last decade, introducing many innovative products. India's insurance industry is vital to the country's economy. Digital Transformation have a drastic impact on the Insurance sector. Digitization results in future innovative designs and launch innovative products which help insurance companies and the customers. Digital innovation is transforming the way how the insurance companies work with industries by integrating IoT devices with health insurance which will also benefit the customers. In this paper, we will analyze and understand how HDFC ERGO has implemented digital transformation that has enhanced operational efficiencies and completely transformed service deliveries and customer experience in the insurance industry.
\end{abstract}

Objectives: To do analysis and review on the digital transformation in the insurance company and how it has impacted the operational efficiencies, service deliveries and customer experience.

Design/Methodology/Approach: This company analysis was done by analyzing and referring different sources like online sources, such as websites, blogs, scholarly articles, web articles, and using Technology Analysis as a framework.

Findings/Result: Digital transformation and how it impacts insurance company in terms of its operational efficiency, service deliveries and customer experience are discussed. Analysis done to find how the organization should stay ahead in implementing the digital technologies and how digital transformation helps the insurance industry to explore new technologies and provides innovative ideas to improve organizational efficiency

Originality/Value: Based on the information and the data available, digital transformation and its impact in the insurance company in the current state is analyzed.

Paper Type: A Case study analysis done on the digital transformation in the HDFC ERGO general insurance company.

Keywords: Insurance sector in India, Indian economy, Digital transformation, Innovation in insurance sector

\section{INTRODUCTION :}

Every insurer should follow the IRDAI. Currently, there are 24 life insurance companies and 33 Nonlife insurance companies are functioning in insurance sector in India. Seven are government agencies. Non-life insurance companies insure our daily activities such as travel, health, auto, motorcycle, and home insurance. Non-life insurers cover our industrial equipment in addition to life insurers. India's general insurance companies offer more than just crop insurance for farmers, mobile phone insurance, and pet insurance. Life insurance companies have recently developed investment prospectuses to provide insurance while increasing the value of the retirement savings account [1]. However, general insurers are still wary of covering homeowners for pure risk. Indian government has taken several initiatives in the past years for the digital transformation of the country. Insurance is one of the industries where the digitization has had its impact. In India, Insurance sales is heavily influenced by digital 
transformation. Digital transformation has impacted sales by $9 \%$ for motor insurance, travel insurance by $12 \%$, life insurance by $13 \%$ and health insurance by $15 \%$. New insurance sales of approx. INR 80 billion are digitally influenced. It is also estimated that the insurance sales because of digital influence may rise to $75 \%$ for non-life insurance and rise to $50 \%$ for life insurance [2]. This shift in consumer behavior toward digital transactions in India will have a substantial impact on online insurance policy sales. Customers are drawn to the digital channel because of the lower cost, ease, and availability of a wide range of product information available for insurance policies comparison [3]. In this paper, the digital transformation of insurance companies are studied and reviewed and how it has impacted the operational efficiencies, service deliveries, and customer experience are discussed with special emphasis on HDFC ERGO, a General Insurance Company that provides a wide range of insurancerelated products in the retail area, including Motor, Travel, Home, Health, and Personal Accident, as well as specialized goods in the corporate space, such as Property, Marine, and Liability Insurance [4].

\section{RELATED RESEARCH WORK :}

Werth, et al [11] created a list of elements that would influence the digital transformation of financial services. These can be political, societal, economic, cost increases, or new technology. Revathi has reviewed the application of IT technologies in insurance, such as artificial intelligence, Big Data, the internet of things, blockchain, and cloud computing, and developed the requirements for an insurer's information system [12]. Eling and Lehmann [5] investigated the value generation process of insurers in the context of IT solution usage.

Impact of digitization and analysis related to different digital technology and its impact in insurance sector are listed in the below table. Different area of study and its focus related to insurance sector will be reviewed so the digital transformation in the insurance company and its impact on the operational efficiencies, service deliveries and customer experience can be analyzed and documented. Table 1 depicts the published research on digital technology related to insurance companies along with the area of study.

Table 1: Summary of published scholarly papers in digital technology related to insurance companies along with the area of study.

\begin{tabular}{|l|l|l|l|}
\hline Sl.no & Area of Study & Focus & Reference \\
\hline 1 & Impact of Digitalization & $\begin{array}{l}\text { The Impact of Digitalization } \\
\text { on the Insurance Value Chain } \\
\text { and the Insurability of Risks }\end{array}$ & $\begin{array}{l}\text { Eling, M., \& Lehmann, M. } \\
\text { (2018) [5] }\end{array}$ \\
\hline 2 & $\begin{array}{l}\text { Advances in Intelligent } \\
\text { Systems and Computing }\end{array}$ & $\begin{array}{l}\text { Digital technology in } \\
\text { insurance and advances in } \\
\text { Intelligent Systems and } \\
\text { Computing }\end{array}$ & $\begin{array}{l}\text { Mustafina, A., et al. (2020) } \\
\text { [6] }\end{array}$ \\
\hline 3 & Digital Insurer & $\begin{array}{l}\text { The Making of a Digital } \\
\text { Insurer: The Path to Enhanced } \\
\text { Profitability, Lower Costs and } \\
\text { Stronger Customer Loyalty, } \\
\text { McKinsey \& Company }\end{array}$ & Catlin, T., et al. (2015) [7] \\
\hline 4 & $\begin{array}{l}\text { Digital related } \\
\text { comprehensive }\end{array}$ & $\begin{array}{l}\text { Digital agendas in the } \\
\text { insurance industry: the } \\
\text { importance of comprehensive } \\
\text { approaches }\end{array}$ & $\begin{array}{l}\text { Bohnert, A., et al. (2019) } \\
\text { [8] }\end{array}$ \\
\hline 5 & Big Data & $\begin{array}{l}\text { Regulating Big Data effects in } \\
\text { the European insurance market }\end{array}$ & Porrini, D. (2017) [9] \\
\hline 6 & Digital Technologies & $\begin{array}{l}\text { AI in Insurance: Hype or } \\
\text { Reality? }\end{array}$ & PWC, (2016) [10] \\
\hline
\end{tabular}




\begin{tabular}{|l|l|l|l|}
\hline 7 & $\begin{array}{l}\text { Digital transformation in } \\
\text { the financial services } \\
\text { sector. }\end{array}$ & $\begin{array}{l}\text { Influencing factors for the } \\
\text { digital transformation in the } \\
\text { financial services sector. }\end{array}$ & $\begin{array}{l}\text { Werth, O., et al. (2020) } \\
{[11]}\end{array}$ \\
\hline 8 & $\begin{array}{l}\text { Technology and } \\
\text { Innovation in Insurance }\end{array}$ & $\begin{array}{l}\text { Present and Future Technology } \\
\text { in Indian Insurance Industry }\end{array}$ & Revathi, D. P. (2020) [12] \\
\hline 9 & Machine learning & $\begin{array}{l}\text { Machine learning applications } \\
\text { in nonlife } \\
\text { insurance. }\end{array}$ & Grize, Y., et al. (2020) [13] \\
\hline 10 & $\begin{array}{l}\text { Blockchain and contract } \\
\text { theory }\end{array}$ & $\begin{array}{l}\text { Modeling smart contracts } \\
\text { using insurance markets }\end{array}$ & $\begin{array}{l}\text { Sheth, A., \& Subramanian, } \\
\text { H. (2019) [14] }\end{array}$ \\
\hline
\end{tabular}

Based on above review of use of digital technology summarized in table 1, it is observed that many digital technologies including artificial intelligence, big data, Internet of Things (IoT), machine learning, blockchain technology, cloud computing are currently used in digital companies that offers insurance as service. As per the principles of industry analysis [15], in this paper, the objectives of analyzing the Indian insurance industry are set for detailed study.

\section{OBJECTIVES OF THE STUDY :}

(1) To comprehend the trends influencing digital transformation in the insurance business.

(2) To analyze the various digital technology used in insurance industries and analyze the same in the HDFC ERGO company.

(3) To understand the impact of digital strategy on the customer experience.

(4) Understanding and analyzing digital technologies that insurance businesses can utilize in order to provide appropriate measures to improve the quality of digital insurance services.

(5) To comprehend and investigate the influence of digital technology on financial performance.

(6) To provide suggestions based on the study of innovation and plan analysis.

\section{METHODOLOGY :}

In this paper, the analysis done using secondary data and information collected from multiple sources such as websites, blogs, journals, articles and also from the Company Website of HDFC ERGO.

\section{OVERVIEW AND TRENDS WHICH DRIVES DIGITAL TRANSFORMATION :}

Digital initiatives open new company opportunities while also improving customer service platforms. It is noticed that roughly $40 \%$ of consumers renew their policies through digital channels that it has established a strong presence on numerous digital platforms. Furthermore, service providers are making good use of digital assets for claim surveys. The insurance industry is being transformed by digital transformation. Automation of laborious operations, digitization of paper forms and records, and artificial intelligence (AI)-powered decision assistance are quickly becoming necessity rather than luxuries. The five major reasons of why insurance companies must be digitalized [16] is listed below:

\subsection{Technology advancement:}

Insurance companies are turning to artificial intelligence and machine learning to help them make important business choices. When insurers use these technologies to massive data sets, they frequently discover previously unknown patterns in the data, allowing them to better serve their clients. Insurance firms can now offer coverage that is considerably more personalized to everyone using advanced analytic and algorithms [17].

\subsection{The role of the adjuster has shifted:}

Insurance adjusters are expected to do field interviews, inspections, and research but they are now expected to do so in near-real time. Adjusters must record critical data on the fly and transmit it to a wide range of stakeholders. Connected devices, smartphone apps, data analytic, and automated support systems assist adjusters in expediting and simplifying the claims process while providing clients with quick, secure, and effective services and insurance. Networked devices also enable insurers to communicate with their consumers more regularly and to offer new services based on data acquired. 
Customers in the insurance industry, in instance, frequently deal solely with agents or brokers; direct client contact has traditionally been limited to contract extensions and the management of insurance claims. As a result, IoT could have a significant impact on customer interactions, allowing businesses to build more extensive and targeted consumer contact [18], [19].

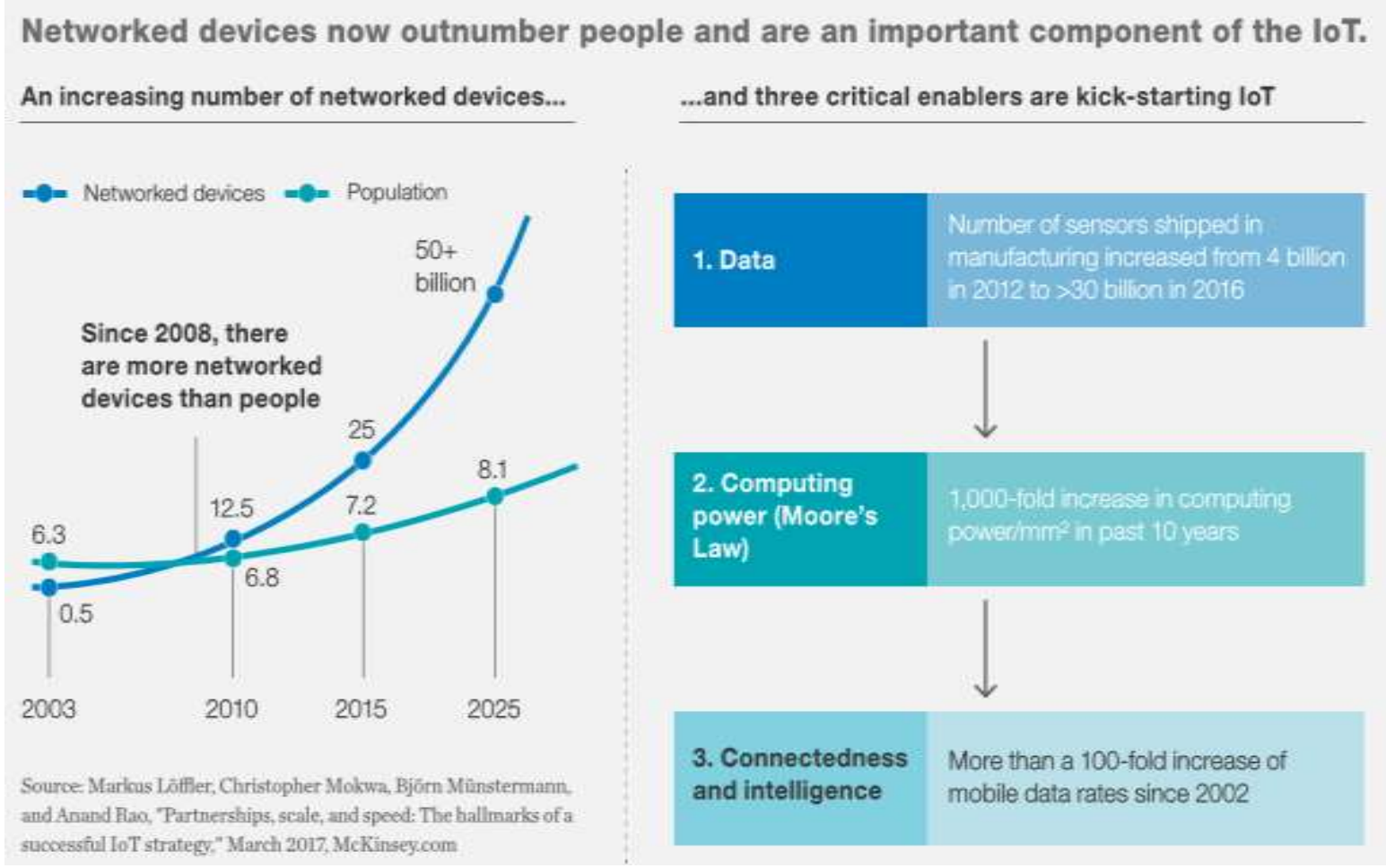

Fig. 1: Networked devices now outnumber people and are an important component of the IoT [18]

\subsection{Cloud computing necessitates:}

The ability to meet changing customer demands, adapt to new business processes, and keep the costs of employing advanced technology under control is driving workflows to the cloud. This necessitates the engagement of back-office personnel with experience in architecting and managing cloud systems.

\subsection{Customer expectations have continuous changes:}

The COVID-19 epidemic has expedited a long-standing shift in consumer behavior and preferences: Access to information 24 hours a day, hassle-free interactions, automated services, and tailored products are the new benchmarks for a positive customer experience. People are also shopping around more than ever before, looking for plans at low prices. Successful insurance firms invest in technology that streamlines workflows in order to attract and keep customers. The figure 2 shows the possible increase in online insurance market because of customer expectation changes.

\subsection{The significance of identity security is being highlighted:}

As insurance firms collect and retain more data to support their digital transformation activities, keeping track of who has access to that data, who should have access, and who is utilizing their access correctly becomes increasingly difficult. An automated identity security solution allows insurers to take a zerotrust approach to regulating access to data and apps, reducing the risks of insider fraud and external data breaches.

Insurance firms are among the most vulnerable businesses to cyberattacks due to the massive volumes of personally identifiable information (PII) they handle and the number of third-party administrators (TPAs) they work with. The figure 3 shows the details of increase in digital buyers. 


\section{Online Insurance Market in INR billion, India}

2019-2024

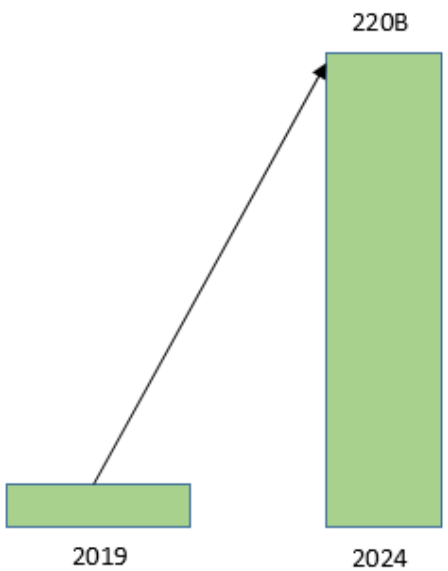

Fig. 2: Online Insurance Market in INR billion, India [16]

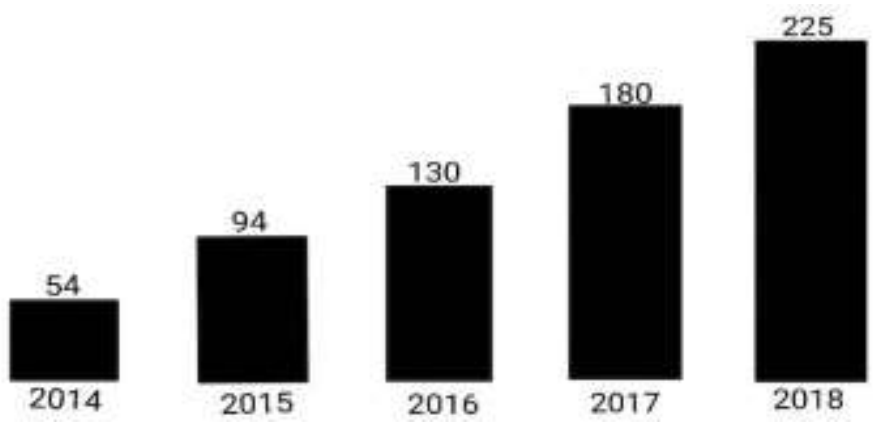

Fig. 3: Digital buyers increase (in millions) [16]

\section{DIGITAL CHANNELS IN INSURANCE COMPANY :}

Evolving and emerging technologies needs to be used in the insurance company to be in pace with customer's expectation. The below points highlight the digital technologies which are currently used:

\subsection{AI Enabled Chabot:}

AI-enabled Chabot 'DIA' on Google Assistant allows users to interact with it via Google Home devices [20]. Users who have Google Assistant installed on their phone will also be able to access DIA. Through this launch, DIA will be available to a larger number of individuals, answering their general insurance queries and providing a superior customer support experience. Customers can utilize DIA to easily identify the nearest network hospital, HDFC ERGO branches or network garage, acknowledge the products supplied by the organization, and even receive answers to numerous general insurance problems [21].

\subsection{Data and Digital technology in Insurance Company:}

Insurance is mainly Data mining and data analytics that provides a lot of insights into customer demographics (behavior, preferences etc.) Opportunities are created based on these insights which give a hand to obtain many models which helps keep up the organization to give the correct product with the finest risk cover at the right for the clients. These data are anchored to provide numerous options to discover new goods that might assist cover the consumer adequately with the best coverage in case of unforeseen events.

\subsection{Omni Channel:}

Every accomplishment has been aided by an Omni channel strategy. A customer can interact with the company with the help of an IVR, Call Centre, Mobile app etc. The HDFC ERGO'S system is also 
connected with online platforms of the B2B Partners. A change made related to or in the partner's system simultaneously gets reflected in the company's system.

\subsection{Self Service Option:}

Recently there is a significant increase in the number of consumers using the self-service option for file claims and the Net Promoter Score (NPS) on this service has been positive. So, company aims for an 80 percent success rate. Customers are at ease making a monetary transaction without speaking with customer support.

\subsection{Digitally enabled insurance products:}

All insurance retail products which have high volume like motor, travel, health etc. are managed using digital technologies. Health product is highly digitalized in such a way that the partners working for HDFC ERGO can book a customer appointment with the diagnostics teams digitally. As underwriting is a critical process for a general insurance firm, the entire underwriting is self-automated. A link is supplied to the customer when there is a break in policy. Customer can shoot the video of the vehicle and do his own inspection. Following that, if certain conditions are met, the claim can be cleared on the same day. $70 \%$ to $80 \%$ of the process in the healthcare insurance is now digital. AI-assisted underwriting is used in the healthcare insurance. Human intervention is required in a few uncommon cases, and they are subjected to further examinations due to certain circumstances.92\% of the policies are processed online and it is increasing to $95 \%$. This means no manual data entry is done for processing policies. Calls to the call center have also reduced [22].

\subsection{Platform for social media integration based on cloud technologies:}

In this digital age, social listening is a must-have for any brand. With customers increasingly adopting digital channels to engage with brands, a cloud-based technology named "Lithium" is being introduced to provide a uniform view of most of the social platforms. Lithium searches the web in real time to provide a feed of how customers perceive and discuss the company. A specialized team of support representatives has been assigned to interact and communicate with these clients via Lithium, as well as to respond to their posts as soon as possible in order to handle their queries or requests. Customers can use the Insurance Community Portal platform to get answers to their questions regarding General Insurance products and services from their peers.

\subsection{Customer prediction using an IVR algorithm:}

IVR solutions provide end-to-end help to customers without requiring them to interact with a customer service agent. A flood of initiatives and processes are centered on the IVR for the customer, which detects their phone number and enables the creation of a differentiated service experience. This is performed through data analytics and segmentation, which allows for improved service standards as well as increased revenue prospects through cross-selling and up-selling to clients. Claim Registration with IVR was created to simplify and speed up the claim notification process.

\subsection{HDFC ERGO insurance app:}

The HDFC ERGO Mobile IPO lets you to acquire an insurance quote via an app. The status of the claim can be tracked via the mobile app, and the process for making a claim can be launched promptly. It is one of the greatest insurance smartphone apps launched by HDFC ERGO for policy users to find cashless hospitals. The HDFC ERGO Mobile App, commonly known as the insurance portfolio organizer, allows customers to read policy wordings, locate cashless hospitals and garages, and get claims handled immediately. This app may be downloaded from the Google Play Store, and the policy is easily accessible.

\section{ANALYSIS OF IT AND AUTOMATION IMPLEMENTATION :}

89 percent of HDFC ERGO plans are booked automatically. Aim is to continue investigating cognitive technologies such as speech analytics, robotics, natural language processing, and advanced analytics to increase operational efficiencies and customer experience. It is believed that Chatbots and robotic process automation will remove manual operations while increasing efficiency. Speech analytic tools are in development stage to assist to get deeper insights into hearing customers' voices and continuously 
improve the quality [23]. With all these technologies, automation of processes is continuously made to enhance operational efficiency.

\section{DIGITAL STRATEGY AND CUSTOMER EXPERIENCE :}

HDFC ERGO has redesigned business operations in the digital age, putting the consumers first. The outcomes were considerable. Turnaround Times (TATs) have been drastically lowered. Improvement has been made in the customer service field, as has the Net Promoter Score (NPS). HDFC ERGO's digital channels accounts for 89 percent of their business. Customers' preferred platforms for requesting service are the website and IVR. Channel partners are also heavily utilizing digital platforms. A query submitted by email or IVR can be tracked online as well.

Business Strategy Model for the Digital Age, this digital strategy is centered on the customer in order to give a consistent experience across several channels. It focuses on the optimal use of mobile technology and offers several self-service options to clients and channel partners for a better experience and faster response. It also works on various facets of digitization to ensure that operations are as lean as feasible. Furthermore, this strategy emphasizes on data-driven decision-making by using Analytics and AI technology.

\section{TECHNOLOGY ANALYSIS FRAMEWORK :}

When implementing digital technologies in the insurance industry, information systems provide not only the ability to automate processes and expand sales channels, but also, to a greater extent, the prospects for strategic business development based on improved customer service within the framework of "input - output," such as expanding insurance coverage. However, the details presented above imply that the largest demand is for IT solutions that boost productivity.

The automation of corporate operations, the enhancement of sales channels' efficiency, and feedback systems Telematics, optical face, object recognition, and block chain technologies are lagging. Based on the proposed systematization of the effects achieved through the implementation of IT technologies, insurers should prioritize the use of IT solutions aimed at reducing the level of internal and external insurance fraud (via the use of artificial intelligence tools, machine learning) and forming a client interface in terms of claims settlement (through the use of artificial intelligence systems). (Based on the Internet of Things, cognitive technologies, big data, and cloud computing), resulting in more openness in the determination of a reasonable insurance pricing. These modifications will raise the perceived value of insurance services in the perspective of consumers. Furthermore, the insurer's improved business model, which is based on IT solutions and is further integrated into the existing architecture of the information system, will enable it to be strategically competitive with other market competitors. New products and services created with emerging new technology like blockchain in industries. Selfdriving cars, for example, will drive demand for a new auto insurance product. This technology has its own set of advantages and disadvantages, such as lower accident rates but increased claim complexity. New type of problem can occur in which hackers can gain control of the vehicle. So, in this case cybercrime insurance coverage is required with the new motor insurance. Having said that, the potential value and applications for using digital to gain a competitive advantage remains unchanged [24].

Artificial Intelligence enabled process and devices are becoming common in all the sectors. AI enabled devices are used in all the sectors like AI enabled voice activated AI assistants. AI can also help to reduce the process time of every process in the insurance sector as accessing data using AI will be faster so the overall turnaround time to complete a process end to end will be fast. Using machine learning algorithm many processes can be automated and by learning continuously the process of automation in the insurance sector can be improved. In the insurance sector, to get insurance and quote requested details are shared by customer to insurance providers. Internet of things will enhance and automates the sharing of data. Virtual assistants are in many insurance platforms and customers query are handled by chatbots. Machine learning and artificial techniques are combined which enables chatbots to interact with the customers in the same way how human do and handles customer's service request, complaints and frequently asked questions. Mobile app is another technology trend which enables customers to access the application from their location and enables customer to check for various insurance premiums available, also compare between different insurance premiums [25]. Various technology trends and digitization reshapes the insurance industry, also helps insurance companies to focus on the customer, improve the pricing and helps to enhance the operational efficiencies. 
10. COMPARATIVE STUDY OF DIGITAL TECHNOLOGY WITH COMPETITORS :

\subsection{ICICI Lombard General Insurance Company:}

Agile methodology for software development and the digital strategy of company has resulted in business continuity and operational efficiency. Digital copies of claims forms can be sent by customers using digital communication channels. Remote doctor consultation added using digital technology. Remote working for the insurance company are managed using Cloud computing. Machine learning (ML) and AI driven solutions are used both in operations and sales, such as RPA and Chabot. Image and video-based inspections, ICR/OCR and algorithm-based claims authorizations were added as a part of these new- technologies [26].

\subsection{Bharti AXA Life Insurance Company:}

To emerge as one of leading insurance firm in India, Digital transformation is a key business driver. MLife, M-Sell, M-Customer and launching data driven initiatives as well as revamping the corporate website are some of the digital transformation initiatives. M-Smart digital solution to support their direct sales force including agents and distributors were launched. Websites were also revamped to offer a superior customer experience that enables visitors to navigate and explore conveniently. 7 new digital platforms launched for its sales personnel, distributors and customers [27].

\subsection{Bajaj Allianz General Insurance Company:}

Android and IOS application with integrated medical check-up process/mobile app are developed to ensure wellness of customers using AI technology. App which uses machine learning algorithm tracks walking and sleeping patterns and make sure that the customer has a healthy lifestyle. Policies are renewed with less turn-around time using machine learning algorithm. The Chabot service is available on company website, company's Facebook page mobile app, and integrated with WhatsApp. For corporate customers who has corporate policies, corporate portal available for all request. Customer self-service mobile app has feature that enables customers to click images of their damaged vehicles and the same can be submit for claim. AI based photogrammetry tool detects damages and certain claims are settled within 30min.

\section{FINANCIAL PERFORMANCE AND DIGITAL INITIATIVES :}

The digital initiatives have been positively impacting the business in terms of financials. 97 percent of retail policies issued digitally as the entire sales process are in digital mode. Self-help tech platform has made customers to use more than 80 per cent of the services in a self-service mode virtually. The above two points will help in increasing the financial growth. In February 2021, covering more than 1.5 crore lives HDFC Ergo has crossed ₹ 10,900 crore in gross premium income on year-to-date basis. $89 \%$ of the business are found to be through digital channels. Channel partners will issue policies using digital platforms or customers will directly purchase insurance policies through various online channels like the website, aggregators or net-banking. The below figure 4 shows the Performance of Health insurance sector in India.

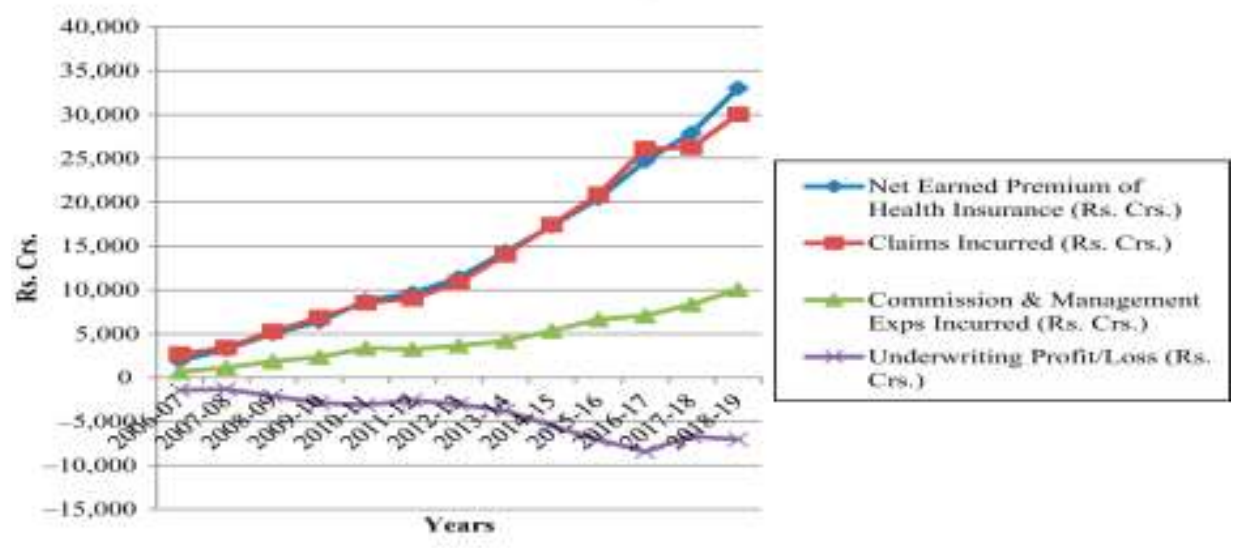

Fig. 4: Data Showing Health Insurance Sector Performance in India [27] 


\section{DIGITAL INITIATIVES AND COVID 19 :}

Understanding the obstacles that customers confront in the present pandemic situation, services are offered that may be obtained promptly and at their convenience. The successful launch and adoption of innovative services such as Overnight Vehicle Repair, Online Self-Survey via a mobile app, Livestreaming inspection from workshops, and quick service access via digital platforms inspired consumer trust and reaped benefits for the Company in FY20. By empowering its customers, customer advocacy activities have increased HDFC ERGO's digital services and offerings. In recent months, there has been a strong emphasis on digitizing contact centers and claims activities because of the pandemics. Automation and process simplification resulted in tremendous success to handle the pandemic period. HDFC ERGO has a strong digital service architecture, which has allowed the company to implement entirely paperless processes. Customers can submit their requests for filing a claim, policy renewals, and changes to existing policies, among other things, from the comfort of customer's own homes using a variety of methods such as the web portal, mobile apps, IVR, chatbots, and email bots [28].

\section{INNOVATION \& FUTURE PLAN ANALYSIS :}

Working with Insuretech start-ups has helped in areas like Chatbot, Robotics, Voice chat and Machine learning.AI tool IDEAS (Intelligent Damage detection Estimation and Assessment Solution) launched for settlement of motor claims. Instant damage detection is supported by this AI tool and in real time the claims are calculated for the surveyors. As an insurance focused incubation center, startups will be launched which would offer innovative services and products and services. Nine startups shortlisted to work with the company in the areas of imaging, block chain and AI. Unique product can be created, and service offerings can be provided to customers. Efforts are being made to create innovative ideas, build an ecosystem for service providers and experimenting started with the block chain technology considering the future-plans. The figure 5 shows the expenditure of insurance companies in technology innovations worldwide [29].

\section{Insurance Companies Spending in Technology Innovations worldwide}

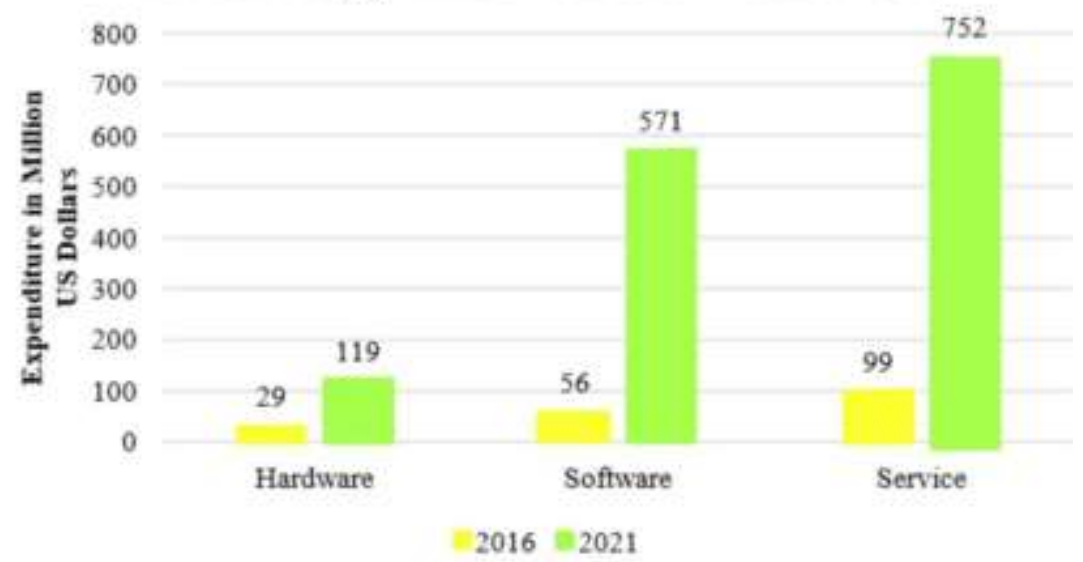

Fig. 5: Insurance Companies Spending in Technology Innovations Worldwide [29]

\section{RECOMMENDATIONS :}

In order to provide operational efficiencies and service delivery to clients, insurance businesses must take several actions on a regular basis to stay ahead of digital technologies and innovations.

- By keeping an eye on emerging trends and breakthroughs in the technology, data, and analytics space, customer experience can always be improved.

- Assure that the company's IT strategy maintains a presence in the innovation ecosystem via technological platforms, FinTech centers, and seminars.

- In IT strategy and architecture, the agile approach must be followed.

- In collaboration with entrepreneurs and disruptors, innovate, develop, and deploy experimental solutions using digital technologies. 
- The launch process evolves in tandem with future technological trends, and the online system in the marketplace evolves swiftly.

- To keep up with increasing demand, processes, technology, and consumer expectations, organizations' cultures and mindsets must evolve.

\section{CONCLUSION :}

As discussed in company analysis methodologies by Aithal et al. [30], technologies used in various companies like data sciences, IoT, mobility, and Artificial Intelligence (AI) will widely change the way the business (insurance companies) operates and provides areas for innovation in products and services. Automation of underwriting and fraud controls could be enabled using AI and analytics [31]. Consumers are bounded to have a high volume of digital footprint as there is an increase of data space. Data when coupled with AI, we can build innovative products catering to specific needs of insurance companies or insurers or agents and insurance can be given at a competitive price. Insurance companies needs to operate through multiple digital channels and should explore more and depend heavily on technologies which includes technologies like Robotics and Artificial Intelligence which will propel organizations to keep up with emerging customer demands and also to survive in the face of the future and also to compete better in an economic environment that is constantly changing in response to technology evolutions.

\section{REFERENCES :}

[1] Insurance News, Opinion \& Analysis | Insurance Business UK. (n.d.). Https://www.Insurancebusinessmag.com. Retrieved August 27, 2021, from https://www.insurancebusinessmag.com/uk/

[2] IRDA - IRDA Journal. (n.d.). Https://Www.Policyholder.Gov.In/. Retrieved August 27, 2021, from https://www.policyholder.gov.in/irda_journal.aspx

[3] Mujalde, D. S., \& Kandari, M. A. (2018). A Comparative Study between Public and Private Insurance Company in India. International Journal of Trend in Scientific Research and Development, 2(2), 1289-1296.

Google Scholar $x^{\top} \quad$ CrossRef 7

[4] What is Health Insurance? (n.d.). Https://Www.Hdfcergo.Com/. Retrieved August 27, 2021, from https://www.hdfcergo.com/health-insurance

[5] Eling, M., \& Lehmann, M. (2017). The Impact of Digitalization on the Insurance Value Chain and the Insurability of Risks. The Geneva Papers on Risk and Insurance - Issues and Practice, 43(3), 359-396.

Google Scholar 7

\section{$\underline{\text { CrossRef }} \not \bar{x}$}

[6] Mustafina, A. A., Kaigorodova, G. N., Alyakina, P. D., Velichko, N. Y., \& Zainullina, M. R. (2019). Digital Technology in Insurance. Advances in Intelligent Systems and Computing, 678-685. Google Scholar ${ }^{7} \quad$ CrossRef $\rtimes$

[7] Catlin, T., Hartmann, R., Segev, I. and Tentis, R. (2015) The Making of a Digital Insurer: The Path to Enhanced Profitability, Lower Costs and Stronger Customer Loyalty, McKinsey \& Company, available at http://www.mckinsey.com/industries/financial-services/our-insights/the-making-of-adigital-insurer, accessed 20 August 2021

[8] Bohnert, A., Fritzsche, A., \& Gregor, S. (2018). Digital agendas in the insurance industry: the importance of comprehensive approaches $\dagger$. The Geneva Papers on Risk and Insurance - Issues and Practice, 44(1), 1-19.

Google Scholar ${ }^{\top}$

CrossRef $x^{7}$

[9] Porrini, D. (2017). Regulating Big Data effects in the European insurance market. Insurance Markets and Companies, 8(1), 6-15.

Google Scholar $x^{\top} \quad$ CrossRef $x^{\top}$ 
[10] PWC (2016) AI in Insurance: Hype or Reality? Available at https://www.pwc.com/us/en/insurance/publications/assets/pwc-top-issues-artificialintelligence.pdf, accessed 20 August 2021.

[11] Werth, O., Schwarzbach, C., Rodríguez Cardona, D., Breitner, M. H., \& Graf Von Der Schulenburg, J. M. (2020). Influencing factors for the digital transformation in the financial services sector. Zeitschrift Für Die Gesamte Versicherungswissenschaft, 109(2-4), 155-179.

Google Scholar $x^{\top} \quad \underline{\text { CrossRef }} \times$

[12] Revathi, D. P. (2020). Technology and Innovation in Insurance- Present and Future Technology in Indian Insurance Industry. International Journal of Engineering and Management Research, 10(1), 21-25.

Google Scholar 7

\section{CrossRef $x^{7}$}

[13] Grize, Y., Fischer, W., \& Lützelschwab, C. (2020). Machine learning applications in nonlife insurance. Applied Stochastic Models in Business and Industry, 36(4), 520-537. Google Scholar $x^{\nearrow \quad \text { CrossRef }} x^{\nearrow}$

[14] Sheth, A., \& Subramanian, H. (2019). Blockchain and contract theory: modeling smart contracts using insurance markets. Managerial Finance, 46(6), 803-814.

Google Scholar $x^{\top} \quad \underline{\text { CrossRef }} x^{\top}$

[15] Aithal, P. S. (2017). Industry Analysis-The First Step in Business Management Scholarly Research. International Journal of Case Studies in Business, IT and Education (IJCSBE), 1(1), 113.

Google Scholar $x^{\top}$

[16] Vaithianathan, S. (2010). A review of e-commerce literature on India and research agenda for the future. Electronic Commerce Research, 10(1), 83-97.

Google Scholar $7 \quad$ CrossRef 7

[17] Belanche, D., Casaló, L. V., \& Flavián, C. (2019). Artificial Intelligence in FinTech: understanding robo-advisors adoption among customers. Industrial Management \& Data Systems, 119(7), 1411-1430.

Google Scholar $\chi^{\top}$

CrossRef

[18] Spender, A., Bullen, C., Altmann-Richer, L., Cripps, J., Duffy, R., Falkous, C., Farrell, M., Horn, T., Wigzell, J., Yeap, W. (2019). Wearables and the internet of things: considerations for the life and health insurance industry. Br. Actuar J., 24(22), 1-31.

Google Scholar ${ }^{\top} \quad$ CrossRef $x^{\top}$

[19] Banafa, A.: IoT standardization and implementation challenges. IEEE Internet of Things Newsletter (2016). $\quad$ https://iot.ieee.org/newsletter/july-2016/iot-standardization-andimplementation-challenges.html. Accessed 26 Aug 2021

[20] Global, E. Y. (2019, April 26). How chatbots and IVAs can enhance customer service for insurers. Https://www.Ey.Com/. https://www.ey.com/en ae/insurance/how-ivas-can-enhancecustomer-service-for-insurers

[21] Chen, Z., \& Ye, R. (2021). Principles of Creative Problem Solving in AI Systems. Science \& Education. Published. https://doi.org/10.1007/s11191-021-00270Google Scholar $x^{\top} \quad$ CrossRef $x^{7}$

[22] Barkur, G., Varambally, K., \& Rodrigues, L. L. (2007). Insurance sector dynamics: towards transformation into learning organization. The Learning Organization, 14(6), 510-523.

$\underline{\text { Google Scholar }} \chi^{\top} \quad \underline{\text { CrossRef }} \chi^{\top}$

[23] Dasgupta, P., Sengupta, K. (2002). E-Commerce in the Indian Insurance Industry: Prospects and Future. Electronic Commerce Research, 2(1), 43-60.

Google Scholar $x^{\nearrow \quad \text { CrossRef }}$ \ 
[24] Lamberton, C. (2017). Impact of Robotics, RPA and AI on the Insurance Industry: Challenges and Opportunities. Journal of Financial Perspectives, 4(1), 8-20.

Google Scholar $\chi^{\nearrow \quad \text { CrossRef }} x^{\top}$

[25] Bhuvana R, \& Aithal P. S. (2020). Blockchain based Service: A Case Study on IBM Blockchain Services \&amp; Hyperledger Fabric. International Journal of Case Studies in Business, IT and Education (IJCSBE), 4(1), 94-102.

Google Scholar ${ }^{\nearrow \quad \text { CrossRef }}{ }^{7}$

[26] Srikanth RP. (2021, January 18). We see endless possibilities for usage of AI in insurance: Girish Nayak, ICICI Lombard General Insurance. Express Computer. https://www.expresscomputer.in/interviews/we-see-endless-possibilities-for-usage-of-ai-ininsurance-girish-nayak-icici-lombard-general-insurance/71729/

[27] Acko, T. (2021, July 22). Insurance sector in India: Overview, IRDAI, Companies, Stats \& Trends. Acko General Insurance. https://www.acko.com/articles/general-info/insurance-sectorindia

[28] Natalija, K. (2019). Insurance, Smart Information Systems and Ethics. The ORBIT Journal, 2(2), $1-27$.

$\underline{\text { Google Scholar }} x^{\nearrow \quad \text { CrossRef }} x^{7}$

[29] Ostagar, A. M. (2018). Innovation and impact of technology in insurance sector. SAARJ Journal on Banking \& Insurance Research, 7(5), 36-47. Google Scholar 7 CrossRef $x^{7}$

[30] Aithal, P. S. (2017). Company Analysis-The Beginning Step for Scholarly Research. International Journal of Case Studies in Business, IT and Education (IJCSBE), 1(1), 118.

Google Scholar $x^{\nearrow}$

[31] Pulluparambil, S. J., \& Bhat, S. (2021). Application of Machine Learning in Google Services- A Case Study. International Journal of Case Studies in Business, IT, and Education, 5(2), 24-37.

Google Scholar $x^{\nearrow \quad \text { CrossRef }}$ \ 